\title{
Corrosion Inhibition of Aluminum by Using Synthesized Dipyridinium Salts
}

\author{
A.A.Ganash ${ }^{*}$, A.Y.Obaid, Shabaan A.K.Elroby, Abou-Elhagag A. Hermas \\ Chemistry Department, Faculty of Science, King Abdulaziz University, Jeddah 21589, Saudi Arabia \\ *E-mail: aganash@kau.edu.sa
}

doi: $10.20964 / 2016.07 .43$

Received: 6 April 2016 / Accepted: 21 May 2016 / Published: 4 June 2016

Some synthesized bipyridinium rings-containing compounds have been used as inhibitors of corrosion of aluminum in $1 \mathrm{M} \mathrm{HCl}$ at $45^{\circ} \mathrm{C}$. Three dipyridinium compounds, DMdPyI, HMdPyBr and BMPyEI, and mono-pridinium ring compound, TMPyI, were studied. Corrosion potential-time, cathodic-anodic polarization and impedance electrochemical measurements, and quantum calculations were applied. The study indicated that these compounds work as anodic inhibitors for $\mathrm{Al}$, except higher concentrations of $\mathrm{HMdPyBr}$ and BMPyEI has additionally some cathodic inhibitive action. The inhibition efficiency of these compounds increased with increasing the inhibitor concentration reaching a plateau at $1 \times 10-4 \mathrm{M}$ and the highest inhibition was observed by the compound BMPyEI. The inhibitors follow Langmuir adsorption isotherm, and the adsorption is endothermic and increase with temperature. The inhibitor compounds are adsorbed mainly physically and spontaneously on the aluminum surface.

Keywords: Corrosion protection, Aluminum, Dipyridinium Salts, inhibitors

\section{FULL TEXT}

(C) 2016 The Authors. Published by ESG (www.electrochemsci.org). This article is an open access article distributed under the terms and conditions of the Creative Commons Attribution license (http://creativecommons.org/licenses/by/4.0/). 